\title{
AGENCIA Y ASOCIACIONISMO EN CONTEXTOS DE VIOLENCIA INSTITUCIONAL: EL ACCIONAR DE MIGRANTES SENEGALESES EN LA CIUDAD DE LA PLATA (ARGENTINA)
}

\author{
Agency and associationism in contexts of institutional violence: \\ actions of Senegalese migrants in the city of La Plata (Argentina)
}

Sonia Raquel Voscoboinik* Bernarda Zubrzycki**

\begin{abstract}
Resumen. El siguiente artículo analiza la agencia de los miembros de una asociación de senegaleses de la ciudad de La Plata (Buenos Aires, Argentina), focalizándose en el surgimiento de la misma y en la participación de Cisé, unos de sus miembros más activos. Al mismo tiempo se describen algunas de las características sociodemográficas más relevantes de la población senegalesa de dicha ciudad. Para la recolección de datos se ha realizado una encuesta, entrevistas con distinto grado de profundidad a los referentes de la asociación y observaciones participantes que incluyeron el acompañamiento a la población senegalesa en instancias de diálogo con funcionarios públicos y la participación activa en una asamblea para intervenir en los casos de violencia contra migrantes senegaleses de la ciudad.
\end{abstract}

Palabras claves: migrantes senegaleses; agencia; asociación.

\begin{abstract}
The following article analyzes the agency of the members of a Senegalese association in the city of La Plata (Buenos Aires, Argentina), focusing on its emergence and on the participation of Cisé, who is one of its most active members. At the same time, some of the most relevant sociodemographic characteristics of the Senegalese population in that city are described. For the data collection, a survey, interviews in varying degrees of depth with the association's referents and participant observations were conducted. The latter included the accompaniment to the Senegalese population in instances of dialog with public officers and the active participation in an assembly to intervene in cases of violence against Senegalese migrants in the city.
\end{abstract}

Keywords: Senegalese migrants; agency; association.

Becaria doctoral de La Universidad Nacional de La Plata. Buenos Aires, Argentina. E-mail: soniavosco@hotmail.com. Orcid: 0000-0001-5849-5593.

** Docente-investigadora de la Universidad Nacional de La Plata. Investigadora del Consejo Nacional de Investigaciones Científicas y Técnicas (Argentina). Buenos Aires, Argentina. E-mail: bernazub@gmail.com. Orcid: 0000-0002-9368-6675. 


\section{Introducción}

Los senegaleses en Argentina se encuentran en una situación de hipervisibilización, al ser migrantes negros en un país que se piensa blanco y estar, además, trabajando como vendedores en el espacio público. Como señala Morales (2010, p. 142), "la invisibilización histórica de los negros en Argentina es condición de posibilidad para que la percepción de estas nuevas presencias propenda al sobredimensionamiento y la extrañeza".

Los agentes de control urbano y la policía, recurriendo a criterios racistas los agreden y realizan decomisaciones irregulares de su mercadería ${ }^{1}$. En este sentido nos interesa indagar ¿Cómo responden los senegaleses a las situaciones de violencia y qué agencias despliegan? Intentaremos dar respuestas principalmente a partir del análisis del accionar de algunos de los referentes de la Asociación Senegalesa de La Plata, una organización de migrantes de esta ciudad, capital administrativa de la provincia de Buenos Aires (Argentina), centrándonos particularmente en el papel desempeñado por Cisé2.

La teoría de la agencia supone que independientemente de las situaciones de subordinación por la cual esté atravesando un grupo social, ya sea colonialismo, racismo, entre otras, las personas siguen conservando la "agencia" entendida como la resistencia a la dominación y como el sustento de proyectos constituidos culturalmente, produciendo o sosteniendo cierto tipo de "autenticidad" cultural o personal (Ortner, 2016).

Retomaremos aquí algunos lineamientos ya trabajados en Espiro, Voscoboinik y Zubrzycki (2016), donde señalamos que la lectura que ofrece Ortner permite relativizar una de las afirmaciones típicas de la modernidad que Stolcke (2004, p. 101) menciona y rechaza "la libertad del/a individuo para forjar su propio destino". Ortner, retomando ideas de Giddens y Sewell, supone la posibilidad de los sujetos de repensar el lugar que ocupan en una determinada estructura social; pero al mismo tiempo, la autora también destaca el carácter histórico, cultural y político de la constitución de las subjetividades, entendiendo a la subjetividad como una conciencia específicamente cultural e histórica.

Coincidimos con Ortner (2016) cuando enuncia que la agencia debe ser entendida como una capacidad construida y distribuida mediante mecanismos socioculturales y de forma desigual; los actores formulan y logran sus objetivos inmersos en una red de relaciones sociales y como carecen

\footnotetext{
1 Las persecuciones por parte de organismos estatales de control son continuas y de larga data, en la ciudad de La Plata hay registro de estas situaciones desde al menos el año 2010 (Espiro, Zubrzycki, 2013). Para Ciudad de Buenos Aires ver Pita y Pacecca (2017).

2 Todos los nombres utilizados son seudónimos.
} 
de un control absoluto de dichos vínculos la agencia debe ser comprendida como producto de una negociación interactiva.

Los datos del presente artículo fueron recolectados a partir de charlas informales y entrevistas en profundidad con algunos referentes de la asociación, así como observaciones en diferentes eventos donde participaron estos referentes. Además, hemos colaborado con asesoramiento en lo concerniente a la conformación legal de la asociación (acompañamiento en diversas instancias de presentación de documentación, traducción de documentos, etc.). Por otro lado, hemos realizado un extenso trabajo de campo registrando el accionar de los organismos de control policial hacia los senegaleses desde el año 2012 hasta la actualidad; incluyendo nuestra participación activa en una asamblea que nace para intervenir en las situaciones de violencia que afectan a los senegaleses de la ciudad.

La caracterización de la población senegalesa platense la realizamos a partir de los datos de una encuesta propia realizada entre septiembre y diciembre del año 2018 a 171 migrantes. Esta encuesta fue diseñada por las autoras junto al Dr. Diego Bermeo ${ }^{3}$. Fue tomada por las autoras, el Lic. Bermeo, algunos integrantes de la Asociación Senegalesa de La Plata, e integrantes de la Asamblea por los Derechos de los Trabajadores Migrantes. Se recogieron datos generales sobre la población encuestada (edad, lugar de nacimiento, pertenencia religiosa, escolaridad, estado civil) y datos sobre la situación migratoria, condiciones de vida y hechos de violencia institucional, particularmente en relación a la policía y control urbano municipal. Durante los cuatro meses, una vez por semana en el horario de 21 a 23 horas se administraron las encuestas. En esa franja horaria era posible encontrar a los senegaleses en sus viviendas. En este proceso el rol desempeñado por Cisé, integrante de la Asociación Senegalesa, fue clave; él era quien se encargaba de informar a los demás senegaleses que serían encuestados y coordinar los las visitas, además jugó un rol fundamental como traductor de las preguntas del español al idioma wolof cuando fue necesario.

\section{Caracterización de la migración senegalesa en la ciudad de La Plata}

Los senegaleses comienzan a llegar muy lentamente a Argentina a mediados de los años 90, intensificándose su presencia diez años después mediante el establecimiento de redes de partida y de llegada bien afianzadas ${ }^{4}$.

3 Docente investigador de la Facultad de Trabajo Social de la UNLP.

4 La migración senegalesa hacia Argentina ha sido ampliamente analizada por varios investigadores. Para más detalle pueden verse trabajos de Espiro, Kleidermacher, Reiter, Sánchez Alvarado, Zubrzycki, entre otros. 
En cuanto a su llegada a la ciudad de La Plata, los primeros senegaleses se establecen en 2006 y actualmente se estima que hay unos 200 viviendo en la ciudad. Los resultados de la encuesta realizada son los siguientes: el 98\% de los encuestados son varones; esta cifra refleja a nivel local lo que sucede a nivel nacional: el número de mujeres senegalesas migrantes en el país es mínimo en relación a los varones.

Casi el $90 \%$ de los migrantes senegaleses que residen en la ciudad tienen entre 20 y 40 años, siendo el resto mayores.

Todos son musulmanes, con un alto porcentaje de pertenencia a la cofradía islámica mouride.

El 41\% no asistió a la escuela (educación formal en idioma francés), un $26 \%$ completó la escuela primaria y un 10\% la escuela secundaria. El $88 \%$ asistió a la escuela coránica (escuela de formación religiosa en lengua wolof y árabe).

En relación a la movilidad previa a su llegada a Argentina, sólo el 30\% residió en otro país por al menos 6 meses. El 81\% lo hizo en Brasil. El resto de los encuestados residieron en España, Italia y otros países africanos.

El 44\% ingresó al continente a través de Ecuador (hasta el año 2015 este país no solicitaba visa para ingresar), el 32\% lo hizo por Brasil (con visa obtenida en la embajada brasilera en Dakar). En ambos casos el posterior ingreso a Argentina es de manera irregular o no autorizada ya que el país solicita visa de ingreso a los ciudadanos senegaleses. Un 6\% ingresó con visa a Argentina y un $4 \%$ lo hizo a través de otros pasos fronterizos (Chile y Bolivia) de manera no autorizada.

El 62\% está casado en Senegal y de ellos la mitad tiene hijos en su país de origen, sólo un 2\% tiene pareja en Argentina.

Al indagar sobre la situación migratoria el 65\% tiene la residencia precaria; el $28 \%$ la residencia permanente; el $8 \%$ se encuentra de manera irregular y el $1 \%$ tiene la residencia transitoria (son unos pocos casos de recién llegados que aún tienen vigente la visa como turistas).

De los migrantes con residencia permanente el $81 \%$ la obtuvo a través del programa de regularización migratoria para senegaleses del año $2013^{5}$. Al indagar sobre el primer trabajo en Argentina el 96\% mencionó la venta ambulante. El restante $4 \%$ obtuvo un trabajo en obras de construcción a través de la vinculación con la Unión de Obreros de la Construcción de la República Argentina filial La Plata (este sindicato empleó tanto a senegaleses con residencia permanente como con residencia precaria, tal como la ley migratoria permite).

\footnotetext{
5 Disposición DNM Nº2/13. Para más datos ver Zubrzycki (2018).
} 
Respecto al trabajo actual el 95\% trabaja en la venta (ambulante o en locales y puestos de ferias) de bijouterie, a la que complementan con otros accesorios como relojes, billeteras y artículos para celulares. Otros venden carteras y sandalias. También gorras y anteojos de sol en verano o guantes y bufandas en invierno.

Algunos datos surgidos de las encuestas son muy esclarecedores respecto a las situaciones de abuso sufridas por parte de organismos de control estatales: cuando se indagó respecto a si la policía o control urbano municipal alguna vez les había retenido/robado la mercadería a la venta, la mitad de los encuestados respondió afirmativamente. Sólo al 24\% le entregaron un acta contravencional y el 93\% no pudo recuperar nunca la mercadería incautada.

\section{Breve presentación del asociacionismo senegalés}

Se ha definido a las asociaciones como la unión voluntaria de personas o grupos en torno a un objetivo común (Giró Miranda, Mata Romeu, 2013). En el caso particular de las asociaciones de migrantes, estas pueden ser pensadas como territorios de redefinición y consolidación de identidad étnica (Maffia et alii, 2005), las mismas intervienen como instancias de visibilización de los migrantes, permiten una inserción social más equitativa en el país receptor, constituyen espacios en los cuales se fortalecen los lazos comunitarios y potencian la emergencia de intervenciones en el ámbito público.

En muchos grupos migratorios, y en nuestro caso migrantes del África subsahariana, aparecen dos dinámicas asociativas diferentes: un primer tipo que serían agrupamientos regidos por criterios de adscripción identitaria (lazos de parentesco, paisanaje, etnía, región de origen, religión); y un segundo tipo que son asociaciones que se rigen por el modelo occidental de la sociedad receptora con una definida estructura organizativa y de gestión (Crespo, 1998). Aunque claramente esta división no es tajante y muchas asociaciones regidas por el modelo occidental se crean sobre la base de agrupamientos de base étnica y/o religiosa.

En Argentina la población senegalesa cuenta con diversos tipos de organizaciones con distintos grados de formalidad y estabilidad, entre las mismas se encuentran las dahiras y las tontinas (asociaciones del primer tipo) y las asociaciones civiles organizadas por criterios de nacionalidad (asociaciones de segundo tipo $)^{6}$.

Las dahiras son formas de asociacionismo muy difundidas en Senegal y reconstruidas en el extranjero, las mismas están basadas en la solidaridad y en la cohesión grupal, su base es religiosa y pertenecen a las diversas hermandades

\footnotetext{
6 Para más información sobre asociacionismo migrante en Argentina, y particularmente
} asociacionismo africano ver: Maffia et alii (2015); Maffia et alii (2018). 
religiosas (o cofradías) presentes en el islam sufí del norte de África, cada una de ellas tiene un líder religioso, una creencia y un ritual específicos; la mouridiyya es la cofradía más numerosa y representativa entre los migrantes, en Argentina también existen otras como la tijaniyya (Zubrzycki, 2011).

Funcionan generalmente a través de reuniones periódicas en las cuales sus miembros, tanto varones como mujeres, se encuentran para rezar y conversar, pero también para exponer sus problemas e intentar resolverlos. Es decir, además de funcionar como espacios de encuentro y oración, canalizan demandas y posibles soluciones, son un marco de referencia cultural y espiritual y un espacio donde se refuerza la solidaridad intragrupal (Riccio, 2008). Sin embargo, a veces hay situaciones específicas que requieren asociaciones del segundo tipo para realizar ciertas demandas en el país receptor.

Las mujeres senegalesas han fundado asociaciones exclusivamente femeninas, tales como "Karambenor", "Ande Nekke Benne" y la "Dahira Mame Diara".

"Karambenor" y "Ande Nekke Benne" constituyen un tipo de asociación que es denominado tontina ("tontine" en francés). Las tontinas son instituciones recurrentes en Senegal y en los diversos contextos migratorios de los senegaleses. Las mismas consisten en agrupaciones ya sea de familiares, amigos y/o conocidos que realizan aportes monetarios periódicamente y mediante un sistema de turnos sus integrantes se llevan el dinero recolectado. Funcionan como un sistema de ahorro colectivo y ocasionalmente fungen como un medio que habilita a sus integrantes el acceso a créditos (en su mayoría, los participantes no pueden obtener créditos en instituciones bancarias por no reunir los requisitos). Las tontinas, además, cumplen importantes papeles sociales tales como fortalecer lazos de amistad y de solidaridad, brindar espacios de socialización, la consolidación de los lazos culturales y religiosos que vinculan a los emigrantes con su país de origen y la búsqueda de protección socioeconómica en el país de recepción (Sow, Tété, 2007).

Entre las asociaciones estructuradas según el modelo occidental, la más conocida y antigua es la Asociación de Residentes Senegaleses en Argentina (ARSA), organización civil de alcance federal que se fundó en el 2007 en la Ciudad Autónoma de Buenos Aires, y en el 2015 logra obtener la personería jurídica; actualmente no cuenta con sede propia y sus miembros se reúnen en espacios cedidos o rentados. ARSA ha sido dirigida por cuatro presidentes, algunos de los requisitos para participar en la elección eran demostrar la pertenencia activa dentro de la asociación y el cumplimiento del pago de las cuotas, cada mandato tiene una duración de dos años ${ }^{7}$. Al no tener Senegal

Para más detalles ver Maffia (2017). 
representación diplomática en Argentina, la asociación emerge como una intermediaria entre los migrantes y el Estado argentino, así como entre el Estado senegalés y su diáspora; ARSA también actúa como mediadora entre los migrantes y las instituciones de ayuda al migrante y al refugiado que brindan servicios gratuitos de asesoramiento y acompañamiento jurídico (algunas dependientes de la iglesia católica o iglesias evangélicas, mientras que otras son organismos no gubernamentales laicos). ARSA además interactúa con otras asociaciones de senegaleses, tales como Karambenor y Ande Neke Benne, orientándolas y asesorándolas en cuestiones legales como por ejemplo obtener su personería jurídica.

En octubre del año 2018 el presidente de la República de Senegal, Macky Sall, estuvo en Argentina reunido con Mauricio Macri (el presidente argentino), el motivo de su visita fue la asistencia a la apertura de los juegos olímpicos de la juventud, y referentes de ARSA lograron acceder a una reunión con él. En la práctica ARSA actúa como representación gubernamental de los senegaleses en el país, por lo cual algunos miembros de la asociación consideran a su dirigente como "el presidente de nosotros acá" (Maffia et alii, 2018).

Pero estas múltiples y significativas funciones que lleva a cabo ARSA impiden ocuparse de situaciones específicas particularmente por fuera de la Ciudad Autónoma de Buenos Aires, por ejemplo, conflictos con organismos de control policial y/o municipal. Es así que en diferentes ciudades han comenzado a organizarse asociaciones de migrantes senegaleses que actúan como interlocutores válidos entre los migrantes y los gobiernos locales.

\section{Los inicios de la organización Asociación Senegalesa de La Plata}

En el año 2014 los senegaleses de la ciudad organizaron una reunión y eligieron a cuatro representantes (Mustafá, Fall, Amadou y Cisé) que oficiaran como voceros del grupo frente a organismos del Estado (municipal y provincial) y que resolvieran cuestiones concretas vinculadas a los senegaleses que residían en la ciudad, por ejemplo, juntar dinero para solventar gastos cuando a alguno de los migrantes Control Urbano les retenía la mercadería, o eventualidades como la enfermedad o muerte y repatriación del cuerpo en caso de fallecimiento.

Previo a esta incipiente organización existen las dahiras mouride y tijan, que comenzaron a funcionar en la ciudad a medida que crecía el número de senegaleses residiendo allí, pero como ya fue señalado, sólo se ocupan de cuestiones religiosas.

En una entrevista Mustafá, uno de los referentes y secretario de la asociación, señalaba: 
¿Hay algún líder entre los senegaleses de la ciudad?

Sí, hay de 3 o 4 personas que si hay problemas nos juntamos y arreglamos. Por ejemplo, son 4 personas que son líder, y si hay problemas, si tienen problema con la justicia, como la policía, son 4. Yo y el chico que está acá [señala a un compañero senegalés que está presente en la entrevista], y hay dos más.

¿Cómo llegan a ser líderes?

Hay otros chicos que están hace muchos años, pero si igual no entienden bien el idioma, y si no pueden comunicarse bien, hay chicos que viven acá hace 10, 11 años, pero no entienden nada, porque no les importa el idioma, quieren plata nada más. Pero los chicos que son líder para los senegaleses los eligieron los chicos (...) elegimos 4 personas, pero todos nos conocemos, sabemos si vos entendés el idioma, y si podés comunicarte (...) Tenemos una asamblea para elegir a las personas, pero cada dos años las renovamos. Las decisiones si queremos hacer una cosa, nos reunimos y la gente que son líderes, toman las decisiones las 4 personas. Se consulta con todos los senegaleses, nos juntamos, charlamos y tomamos las decisiones. No podemos tomar una decisión sin avisarles a los chicos. (La Plata, 2019)

Uno de los criterios para elegir a estos referentes en el 2014 fue el buen manejo del español.

Varios de los referentes actuales de la Asociación Senegalesa de La Plata (ASLP) habían participado en diversas instancias de diálogo y negociación con miembros de la Municipalidad de dicha ciudad, con otros organismos estatales y con organizaciones de Derechos Humanos antes de la conformación de la asociación como tal.

Son estos mismos referentes los que inician un diálogo con el municipio intentando frenar la persecución que sufrían los vendedores senegaleses. Es el caso de Fall, quien en julio de 2016 participó en una reunión en la sede platense de la Secretaría de Derechos Humanos y Pluralismo Cultural de la Nación donde estuvo presente el Director Nacional de Pluralismo e Interculturalidad, reunión a la que se convocó a representantes de los migrantes senegaleses y académicos que trabajamos con estos migrantes para discutir la situación de acoso y violencia de la que eran (y son) parte. Un mes después Fall, junto a otros dos senegaleses, participa en una reunión en la Municipalidad organizada por la mencionada Secretaría de Derechos Humanos, reunión convocada nuevamente para analizar e intentar dar solución a las situaciones de violencia en la vía pública.

Antes de la conformación de la Asociación Senegalesa de La Plata, los referentes elegidos a nivel local actuaban en nombre de ARSA, que intervenía para realizar las negociaciones con las autoridades municipales y resolver 
conflictos. Tiempo después, cuando ASLP comienza a tomar forma, Fall señalaba las diferencias entre ARSA y la Asociación Senegalesa de La Plata:
ARSA podemos decir que es como una vieja asociación, porque tiene casi 7 u 8 años son las mismas personas, son el mismo grupo, no está cambiando, puede ser totalmente diferente con La Plata, porque estamos aprendiendo a organizar, para más cerca más reunidos, para tener más fuerza, para tener menos problemas y más soluciones. Muy diferente los problemas que tenemos aquí a los problemas que tienen ARSA. ARSA es una asociación federal, no es como nosotros una asociación provincial, puede ser más cerca de las autoridades para arreglar nuestros problemas más cerca. Saber que la gente de capital totalmente diferente a la gente de provincia, más grande, tener muchos lugares con grupos muy diferentes, aquí en La Plata queremos resolver nuestros problemas. (Entrevista, La Plata 2018)

En la mencionada reunión de agosto de 2016, son las propias autoridades municipales y de la Secretaría de Derechos Humanos quienes sugieren la formalización de una asociación ya que, según sus términos, necesitan tener como interlocutores a alguien reconocido y formalizado institucionalmente. Sin embargo, la asociación logra formalizarse gracias a esta estructura organizativa previa que funcionaba entre el grupo y que en la práctica cumplía las mismas funciones que la asociación.

En septiembre de 2016 comienzan los trámites para crear legalmente la asociación, lo que implicó redactar un estatuto, conformar la lista de los 15 integrantes de la comisión directiva, seleccionando personas que cumplieran con los requisitos formales (como por ejemplo tener residencia permanente y domicilio en la ciudad de La Plata) y reunir el dinero necesario para certificar las firmas de los integrantes. Desde mediados de 2017 la Asociación Senegalesa de La Plata se encuentra tramitando la personería jurídica.

Al conformarse la asociación son los migrantes varones quienes asumen los roles del comité directivo, senegaleses que se dedican en su mayoría a la venta ambulante y/o en ferias, a excepción de uno de ellos que es empleado de una empresa constructora. Tener documento de identidad es un requisito fundamental, y al igual que la elección de los referentes en el año 2014, para ocupar los cargos deben tener buen manejo del idioma español.

Para comunicarse con los senegaleses de la ciudad, los miembros utilizan principalmente un grupo de whatsapp, que ya existía previo a la formalización de ASLP. Son tres de los referentes elegidos en 2014 quienes siguen ocupando los cargos más altos y actuando como voceros de la asociación hasta tanto pueda constituirse una comisión directiva votada por todos los miembros de la asociación. Es singular el caso de Cisé, quien se encuentra residiendo en Argentina de manera irregular, ya que le fue negada la renovación de la 
residencia precaria cuando su pedido de refugio fue finalmente rechazado, y por lo tanto no tiene la documentación requerida para formar parte de la comisión directiva de ASLP. Pero es un referente elegido por los senegaleses y de hecho es uno de los más activos en cuanto a su participación en eventos públicos, charlas, notas periodísticas, etc. El haber vivido seis años en España antes de llegar a Argentina le permite un manejo del idioma muy fluido.

\section{ASLP y su interacción con otras agrupaciones de la sociedad civil. La participación de Cisé}

En diciembre de 2017, miembros de la Asociación Senegalesa tienen una mesa de diálogo en la municipalidad con concejales de la ciudad. Cisé participó en este encuentro y su balance fue que los concejales no escucharon en ningún momento sus necesidades, los concejales proponían talleres de formación profesional, pero no se comprometían a dejarlos trabajar en la calle, la cual constituye su principal fuente laboral hoy día. Desde este momento Cisé comienza a tener una postura abiertamente en contra de cualquier arreglo que implique sacar a los vendedores senegaleses de la calle. Sin embargo, como veremos más adelante, no es una postura consensuada con todo el grupo.

A mediados del 2018, a raíz de los incrementos de los operativos de control urbano en la ciudad de La Plata, y un nuevo caso de violencia institucional ejercido contra un vendedor senegalés, la Coordinadora Migrante y la Consejería para Migrantes (un espacio de trabajo con migrantes en la Facultad de Trabajo Social de la Universidad Nacional de La Plata) convoca a organizaciones de DDHH, a funcionarios, académicos, estudiantes universitarios y a migrantes a una reunión para establecer medidas colectivas para frenar los atropellos por parte de control urbano y la policía. En esa primera reunión estuvieron presentes formalmente como miembros de la ASLP varios senegaleses. A partir de ese momento se conforma la Asamblea por los Derechos de los Trabajadores Migrantes, la cual tuvo reuniones periódicas durante el resto de ese año para llevar adelante diferentes estrategias.

En este espacio asambleario se destacó nuevamente la figura de Cisé, quien asistió con regularidad a los encuentros y actividades de la Asamblea.

Varios fueron los ejes de trabajo que emergen con la Asamblea. Por un lado, los talleres sobre los derechos de los migrantes senegaleses, en dichos encuentros de carácter mensual se abordó la ley de migraciones, el DNU 70/17, el derecho a la protesta, la ordenanza municipal que prohíbe la venta ambulante, el proceso de regularización migratoria, entre otros contenidos. Al primer taller asistieron unos 90 senegaleses, en los cuatro talleres restantes el número se mantuvo entre 45 y 50 senegaleses. Cisé fue el encargado de convocar a la comunidad, uno de los desafíos que tuvo que enfrentar Cisé fue 
encontrar un lugar y un día en el cual se pudieran dictar los talleres, así como también garantizar la asistencia de los senegaleses; él comentaba en cada una de las reuniones que estarían presentes sólo aquellos senegaleses interesados en aprender sobre sus derechos, ya la asistencia no constituía una obligación. Una de las propuestas iniciales de la asamblea fue utilizar el espacio de las dahiras una vez al mes para dictar estos talleres, pero parte de la comunidad no estuvo de acuerdo en utilizar estos espacios religiosos para ese cometido. Finalmente se decide utilizar una casa deshabitada (cuyo dueño conocía a algunos senegaleses) una vez al mes desde las 22 o $23 \mathrm{hs}$.

Otra de las actividades que surgen a partir de la Asamblea es el diseño e implementación de una encuesta, con miras a contar con información fidedigna sobre las condiciones socio-económicas y migratorias de los migrantes senegaleses. Cisé, Mustafá y Tidiane fueron los que organizaron las visitas a las casas de los senegaleses para encuestar, los que informaron de que se trataba la encuesta y también actuaron como traductores cuando fue necesario.

Por otro lado, la Asamblea se abocó a la tarea de crear un protocolo contra las detenciones a trabajadores migrantes, el mismo fue presentado de forma pública en un evento celebrado el 12 de septiembre en la puerta del rectorado de la universidad. Allí los referentes de la asociación, junto a otros trabajadores migrantes tomaron la palabra y comentaron las violencias que estaban sufriendo y los motivos por los cuales arribaron a Argentina.

Como ya hemos señalado, las personas conservan la agencia, la resistencia a la dominación y el sustento de proyectos constituidos culturalmente "viviendo una vida significativa desde el punto de vista cultural en situaciones de dominación a gran escala ejercida por un otro poderoso" (Ortner, 2016, p. 165). Algunas cuestiones relativas a la presentación del protocolo dan cuenta de ello; específicamente el formato que adquirió este accionar colectivo. Mientras que los integrantes de la asamblea sugieren realizar una protesta en la puerta de la municipalidad junto a una radio abierta, los referentes senegaleses, y particularmente Cisé, desde el inicio pusieron reparos a este tipo manifestación. A Cisé le preocupaba que su comunidad fuera tildada de violenta y problemática por los medios de comunicación hegemónicos de la ciudad. De esta forma, Cisé opta por una propuesta más pacífica: realizar la presentación pública del protocolo en el patio de la universidad de la ciudad. Él comenta en varias oportunidades su preocupación de que su actividad se confundiera o superpusiera con las diversas marchas que tuvieron lugar ese mismo día (como por ejemplo la manifestación de los despedidos del Astillero Río Santiago). Por otra parte, ese día los senegaleses vistieron iere wolof (ropa tradicional de Senegal), pusieron música de Senegal en los altoparlantes y una de las mujeres senegaleses bailó un poco antes del inicio del acto. Al finalizar la 
presentación los miembros de la asociación invitaron a los asistentes y curiosos a que se sacasen fotos con los senegaleses que se encontraban allí. A pesar de que se trataba de una instancia para denunciar algo bastante preocupante como lo es la violencia institucional hacia los migrantes senegaleses por parte del municipio, los senegaleses le dieron una impronta no tan trágica aprovechando el espacio para visibilizar diversos aspectos de la cultura senegalesa. Los miembros más activos de la asamblea pensaron que solamente Cisé tomaría la palabra en la mesa de prensa, ya que esa era la idea original, pero los miembros de la asociación deciden hacer circular el micrófono y que diversos senegaleses allí presentes contaran su experiencia. En síntesis, la dinámica de la presentación del protocolo fue completamente diferente a la cual había imaginado los participantes de la asamblea, lo cual constituye un indicio de que la asociación y la comunidad senegalesa logra apropiarse de esa instancia dándole su propia impronta.

Durante los días previos y posteriores a la presentación del protocolo, Cisé fue convocado por diversos medios de comunicación para visibilizar el conflicto. En una de estas intervenciones en los medios, detalló la importancia política de conocer sus derechos como migrante y como vendedor ambulante:

el mensaje que quiero transmitir a la municipalidad o al intendente es que sabemos nuestros derechos y que estamos todos los días aprendiendo las leyes de acá, para saber las leyes que tenemos. Hay compañeros abogados que me enseñan lo que es la constitución de este país y los derechos que tenemos por ser inmigrantes y los derechos que tiene que cumplir ellos en los operativos. Sabemos que el control urbano que viene a buscarnos a nosotros, no cumplen nada para ir contra nosotros. El mensaje que quiero dar es que ellos sepan que nosotros conocemos nuestros derechos, y estamos esperando que ellos hagan su trabajo como deben, y que no lo hagan por ser más fuertes que nosotros, por ser policías o ser argentinos. (...) Sabemos que la policía no tiene que discriminarnos. (La Plata, 2018, entrevista realizada para el programa televisivo Inconsciente Kolectivo)

Si bien en el desarrollo de las distintas actividades participaron varios miembros de la asociación, se destacó el rol de Cisé, fue él quien asistió a la mayor parte de las entrevistas en los medios y quién concurrió a la mayoría de las reuniones de la Asamblea y con funcionarios públicos.

Durante estos mismos meses miembros de la Asociación tuvieron diversos encuentros con la Comisión Provincial por la Memoria. Como producto de estos encuentros se filman unos videos en los cuales se difunden los derechos de los migrantes senegaleses. Una vez más Cisé ocupa en estas actividades un rol destacado. Mustafá asiste a algunas de las reuniones, pero no toma la palabra y prefiere no participar en la filmación de los mismos videos (en una versión traducida en wolof). La falta de participación y compromiso de otros 
senegaleses en este tipo de actividades, eran motivo frecuente de quejas por parte de Cisé.

En una oportunidad, el vicepresidente de ASLP señalaba las dificultades de los senegaleses para involucrarse en las actividades de militancia:

acá la mayoría vive diariamente de lo que trabajan en la calle, encima, las familias africanas son muy grandes, si me hago cargo de mi familia son mi padre y sus tres mujeres, más las dos mías, más mis hermanos, tanto es una familia grande, no una familia chiquitita. Si estoy trabajando diariamente ganando diariamente por dos o tres días, sabes lo que tengo que tener, ahí se va a afectar mucho con mi familia. Yo estoy trabajando de noche, por eso pude hoy asistir, pero si estaba trabajando de día no podía venir hoy. (Entrevista, La Plata 2018)

Estas palabras de Amadou señalan las dificultades diarias que enfrentan las organizaciones de los migrantes.

La postura de Cisé era muy diferente: "no van donde no les interesa y no avisan", respondía visiblemente enojado.

Lo anterior puede entenderse si pensamos que la agencia está distribuida en forma desigual, algunos la tienen y otros no, algunos tienen más y otros menos, y si bien parece una cualidad individual, las personas "siempre están integrados en redes de relaciones, bien de afecto y solidaridad, bien de poder y rivalidad, o, con frecuencia, una mezcla de ambas. Sea cual fuere la "agencia" que parezcan "tener" como individuos, en realidad esta siempre se negocia de manera interactiva" (Ortner, 2016, p. 175).

El 31 de octubre de 2018 en la ciudad de La Plata se realiza una marcha para repudiar el código de Convivencia que quería ser implementado por la actual gestión administrativa de la ciudad. La población senegalesa de La Plata participa por primera vez de forma masiva en esta ciudad en una marcha. Allí nuevamente la figura de Cisé juega un rol protagónico, y es él quien habla con los medios de comunicación y explica porque dicha reglamentación es regresiva y perjudicaba a ese colectivo migratorio.

Tiempo después se realiza otra reunión en la Municipalidad en la que participa un concejal, miembros de ASLP y de la Asamblea. En ese encuentro Amadou sostiene:

(...) queremos tranquilidad y trabajar como corresponde. Por ejemplo a mí me encantaría estar en mi país y ser el presidente (ríe), pero me tocó venir a Argentina para luchar, no vengo a Argentina para robar y hacer cosas que no me corresponden a todas las comunidades senegaleses venir por necesidad, no para otra cosa, acá en La Plata somos pocos, hoy día estamos sufriendo bastante acá en La Plata, violencia, de todo estamos sufriendo, el control urbano y la policía local, encima si detienen a los chicos, los llevan a la comisaría y les arman causa, por vendedor 
ambulante, no es un delito, es una infracción de todo lado, pero vendedor ambulante todos saben que no es un delito.

\section{Cisé por su parte sostuvo:}

Nosotros lo que más nos gusta es que mantengamos el lugar, porque mejor en otro lugar no vamos a estar (...) nosotros lo único que queremos es estar trabajando y ganándonos la vida nada más, no queremos nada que sea ilegal, por ejemplo si digo ilegal, no se las leyes de acá, por ahí lo que estamos haciendo capaz no es legal, pero bueno no tenemos otra cosa que hacer, entonces lo único que podemos hacer es eso hasta que conseguimos algo mejor, o algo legal, eso es lo primero, por eso sufrimos la violencia de control urbano que los están ayudando la policía. Pero nosotros sabemos que no podemos estar en la calle ¿Pero si dejamos la calle donde nos vamos? ¿Y de que vamos a vivir? (...) Nosotros también estamos dispuestos si hace falta que pagamos impuestos como siempre dicen "que estos negros no pagan impuestos", nada, estamos dispuestos a pagar lo que corresponde a lo que hacemos y si lo ponen lo pagamos, pero que corresponde a lo que hagamos, que no nos digan también una cifra que supere mucho más a lo que estamos haciendo, que nos digan algo que corresponde a lo que hacemos y lo respetamos. Es eso nada más.

Estas palabras de Cisé son en respuesta a un proyecto municipal de crear una feria en las afueras de la ciudad, proyecto con el cual este referente no acuerda ya que, según piensa, no les resultará rentable en términos económicos.

El empadronamiento municipal de vendedores ambulantes es voluntario e implica inscribirse en un listado a partir del cual posteriormente serían convocados como feriantes de un galpón ubicado en las afueras de la ciudad.

Esta última discusión al interior de la comunidad constituyó un punto de inflexión en la trayectoria del activismo de Cisé, quien les había pedido a todos los senegaleses no empadronarse argumentando que esto los perjudicaría a largo plazo, este galpón al encontrarse alejado de la zona céntrica y además requerir del pago de un alquiler para poder abrir un puesto allí, sería finalmente menos redituable que la venta ambulante en el centro de la ciudad, aún con el peligro constante de la decomisación de la mercadería. Algunos senegaleses desoyeron su pedido y se anotaron de todas formas.

Incluso Fall, el presidente de la asociación, se inscribió y posteriormente ofreció asesoramiento a los demás senegaleses para empadronarse.

Ante esta situación, a principios de 2019 Cisé decide finalmente alejarse de la vida de la asociación y de las actividades de la asamblea ${ }^{8}$. Él mismo comenta ante miembros de la asamblea, a propósito de su alejamiento de

8 Un análisis detallado sobre la participación asociativa y el distanciamiento de las asociaciones por parte de los migrantes puede leerse en Lacomba Vàzquez y Giner Monfort (2013). 
las actividades para visibilizar los conflictos de la comunidad, que tiene "una personalidad muy fuerte, y que le dice a los demás chicos lo que deben hacer, pero ellos no le hacen caso", sumado a ello, en estas discusiones los chicos le pueden llegar a "responder mal"; para evitar estas situaciones él decide alejarse de todas las actividades que implican una exposición de su persona y prefiere concentrarse en sus actividades laborales de venta ambulante. Respecto a su participación en la asociación señala que él a partir de ahora se limitará a derivar a los senegaleses que encuentren dificultades con los contactos de abogados, académicos, personas que trabajan con los $\mathrm{DDHH}$, periodistas de medios alternativos, entre otros.

Como señalamos antes, la agencia siempre se negocia de manera interactiva. En este sentido, nos recuerda Sherry Ortner, las personas no son agentes libres que tienen la capacidad de formular y lograr sus objetivos en un vacío social; también carecen de la capacidad de controlar por completo las relaciones para alcanzar esos objetivos (Ortner, 2016).

\section{Reflexiones finales}

La conformación de Asociación Senegalesa de La Plata tanto en su versión inicial del año 2014, como en su versión más reciente (en la cual está tramitando su personería jurídica), emerge como una respuesta a los casos de violencia institucional ejercida contra dichos migrantes. Es decir, el asociacionismo puede ser comprendido como una de las agencias desplegadas por los senegaleses para afrontar esta problemática.

Hay que resaltar que la agencia de los senegaleses de la ciudad no se reduce al proceso de conformación y formalización de su asociación, esto quedó ejemplificado con el caso de Cisé, uno de los referentes de la asociación quien desarrolló también otras agencias tales como su participación en la asamblea y en las actividades que se desprendieron de la misma. Por otra parte, a partir de nuestro recorrido, podemos afirmar que la agencia no está compuesta por metas homogéneas entre dichos migrantes.

Por el contrario, la agencia siempre debe ser comprendida como producto de una negociación, en el caso particular de Cisé hubo, por un lado, una negociación con los miembros activos de la asociación y de la comunidad senegalesa, y por el otro con los actores externos a la comunidad. Con la comunidad Cisé debió discutir varias cuestiones, entre ellas: el lugar y momento en los cuales se dictarían los talleres de derechos, la participación de la comunidad en la presentación del protocolo y, el empadronamiento de la municipalidad de vendedores ambulantes, entre otros asuntos. En las negociaciones los sujetos carecen de un control absoluto de los vínculos y por lo tanto no tienen asegurado el éxito de sus proyectos que motorizan sus accionares. En el caso de Cisé su proyecto de defender los puestos ambulantes, 
plan que incluía el rechazo por parte de toda la comunidad senegalesa de la propuesta de la municipalidad de trasladarlos a un galpón ubicado en las afueras de la ciudad, y como contrapropuesta el pago al municipio de un monto razonable de dinero por la actividad comercial realizada en la vía pública, fue desafiado por algunos senegaleses. El fracaso de su proyecto político, sumado a las tensiones que se generaron entre él y algunos de los senegaleses de la ciudad lo conducen a optar por alejarse de las actividades políticas y sociales. Una vez desvinculada la asociación de la asamblea, principalmente a partir del cese de las actividades de Cisé, se inicia una nueva etapa de repliegue de la asociación, sólo esporádicamente alguno de los integrantes de la comisión directiva sale a la esfera de lo público a dar charlas, etc., por invitación de alguno de los actores de la asamblea u otros actores involucrados en la defensa de los derechos de las personas migrantes.

Hemos mencionado que la agencia debe ser entendida como una capacidad que es construida y distribuida mediante mecanismos socioculturales y de forma desigual, en este sentido resta profundizar en futuras investigaciones como se da esta emergencia de la agencia en los referentes senegaleses, es decir problematizar quiénes son aquellas personas que han accedido a los puestos de la comisión directiva de la Asociación Senegalesa de La Plata y se han involucrado de forma activa en la vida de la asociación. Consideramos que a futuro esto puede abordarse desde la teoría de la interseccionalidad, enfoque que habilita a realizar una reconstrucción compleja del tejido de relaciones sociales y de las posiciones de los sujetos. La teoría tiene potencial analítico para comprender la desigual construcción y distribución de la agencia dentro de la comunidad de migrantes senegaleses de la ciudad de La Plata.

\section{Bibliografía}

CRESPO, Rafael. Asociacionismo negroafricano en una región de la Unión Europea.

Dinámica comunitaria y espacios de participación sociopolítica. Studia Africana, n. 10, p. 33-46, 1998.

ESPIRO, María Luz; ZUBRZYCKI, Bernarda. Tensiones y disputas entre migrantes africanos recientes y organismos de control estatal. El caso de los senegaleses en la ciudad de La Plata. Question, n. 39, p. 109-121, 2013.

ESPIRO, María Luz; VOSCOBOINIK, Sonia; ZUBRZYCKI, Bernarda. Enfrentando el racismo institucional. Análisis de dos casos de migrantes senegaleses en Argentina (2012-2016). REMHU, Revista Interdisciplinar da Mobilidade Humana, n. 48, p. 63-78, 2016.

GIRÓ MIRANDA, Joaquín; MATA ROMEU. Las estructuras asociativas de los senegaleses en España. Revista Internacional de Sociología, v. 71, extra 1, p. 91-115, 2013.

LACOMBA VÁZQUEZ, Joan; GINER MONFORT, Jordi. La participación en asociaciones de los inmigrantes africanos. Vías de interpretación del 
distanciamiento asociativo. Revista Internacional de Sociología, v. 71, extra 1, p. 67-89, 2013.

MAFFIA, Marta. Construcción y renovación de liderazgos en organizaciones de migrantes africanos en la Argentina. El caso de la Asociación de residentes senegaleses en Argentina (ARSA). In: MAFFIA, Marta; ZUBRZYCKI, Bernarda (orgs.). Africanos y afrodescendientes en Argentina: prácticas, representaciones, narrativas y memorias. Buenos Aires: Biblos, 2017, p. 99-128.

MAFFIA, Marta; BALLINA, Sebastián; MONKEVICIUS, Paola. Las asociaciones de inmigrantes extranjeros y sus descendientes en la provincia de Buenos Aires (Argentina). Espacios y tiempos de identidad desde una perspectiva antropológica. Studi Emigrazione, n. 42, p. 625-642, 2005.

MAFFIA, Marta; MONKEVICIUS, Paola; ZUBRZYCKI, Bernarda; AGNELLI, Silvina; OTTENHEIMER, Ana. Dinámicas asociativas entre los inmigrantes africanos subsaharianos en la Argentina. In: MALOMALO, Bas'llele; FONSECA, Dagoberto José; KABUNDA BADI, Mbuyi (orgs.). Diáspora africana e migração na era da globalização: experiências de refúgio, estudo, trabalho. Curitiba: Editora CRV, 2015, p. 89-106.

MAFFIA, Marta; MONKEVICIUS, Paola; ESPIRO, Luz; VOSCOBOINIK, Sonia. Formas Organizativas y Liderazgo entre inmigrantes africanos subsaharianos recientes. In: Migraciones Internacionales. Reflexiones desde Argentina. Buenos Aires: Organización Internacional para las Migraciones, n. 3, 2018, p. 9-28.

MORALES, Orlando Gabriel. Nuevas dinámicas migratorias globales y representaciones locales sobre los negros en Argentina. El caso de las percepciones de agentes de la Policía bonaerense sobre recientes migrantes africanos. Sociedad y Discurso, n. 18, p. 121-148, 2010.

ORTNER, Sherry. Antropología y teoría social. Buenos Aires: UNSAM Edita, 2016.

PITA, María Victoria; PACECCA, María Inés. Territorios de control policial: gestión de ilegalismos en la Ciudad de Buenos Aires. Ciudad Autónoma de Buenos Aires: Editorial de la Facultad de Filosofía y Letras Universidad de Buenos Aires, 2017.

RICCIO, Bruno. Les associations de Sénégalais en Italie. Construction de citoyenneté et potentialités de co-développement. Revue Asylon(s), n. 3, 2008. Disponible en: <http://www.reseau-terra.eu/article714.html>.

SOW, Papa; TÉTÉ, Kokouvi. Estalvis populars Africans a Catalunya: Tipus i formes submergides de pràctiques financeres dels immigrants. Informe final, Barcelona: Fundación Jaume Bofill, 2007.

STOLCKE, Verena. La mujer es puro cuento: la cultura del género. Estudios Feministas, v. 12, n. 2, p. 77-105, 2004.

ZUBRZYCKI, Bernarda. Senegaleses en Argentina: un análisis de la Mouridiyya y sus asociaciones religiosas. Boletín Antropológico, v. 81, n. 1, p. 49-64, 2011.

ZUBRZYCKI, Bernarda. Migración no autorizada y procesos de regularización en Argentina: el caso senegalés. Revista del CESLA. International Latin American Studies Review, n. 22, p. 367-382, 2018. 